lumbar segments of the cord. Major Jones states that this distribution of hyperæsthesia is found in malaria and trench fever, and in no other disease. If these findings are confirmed it may be of great help in the diagnosis of these chronic subjects of trench fever, who are apt sometimes to be considered as "lead swingers" or, at least, exaggerators, when they are really suffering from a definite and disabling condition.

The question of how long this chronic trench fever may last cannot yet be settled. The longest duration that I have yet noticed is a little over one year, but it is probable that it may go on for much longer than this. Patients are usually not very ill-only in low general health, with various painsand so they are soon transferred to a convalescent camp, or put in low categories, where their slight fever is apt to be overlooked. Since I have asked at our convalescent hospitals that such cases have their temperatures taken regularly I have found a number who would otherwise probably have been missed. The resemblance of this condition to malarial cachexia is, in many ways, so great that $I$ venture to suggest the name-trench fever cachexia-for it.

\section{A NOTE ON THE VALUE OF}

\section{GERMINATED BEANS' IN THE TREAT- MENT OF SCURVY,}

AND SOME POINTS IN PROPHYLAXIS.

BY H. W. WILTSHIRE, D.S.O., M.D. САMB., F.R.C.P. LOND.

PHYSICTAX, EING'S COLLEGE HOSPITAL; TEMPORARY MAJOR, R.A.M.C., NO, - GENERAI HOSPITAL.

\section{I. - The Value of Germinated Beans in Treatment.}

IN describing the distribution among foodstuffs of the vitamines needed for the prevention of beri-beri and scurvy Dr. Harriette Chick and Miss E. Margaret Hume ${ }^{1}$ have demonstrated by animal experiments that germinated pulses are richly endowed with antiscorbutic vitamine, and they make the following practical suggestion: "To prevent scurvy, if a supply of fresh fruit or vegetables is not procurable, germinated pulses should be added to the diet."

Many Serbian soldiers were treated for scurvy in this hospital in 1917, and when the disease became prevalent again this year an attempt was made to test the value of these germinated pulses in treatment. Unfortunately, no suitable seeds were forthcoming for some time. All the lentils supplied were decorticated and so would not germinate, peas could not be obtained, and beans, though expected daily, took over a month to arrive. In the meantime over three-quarters of the clinical material, including all the best cases, had been admitted and treated by other means. After beans were at last received comparatively few and slight cases became available for the test, but the results obtained were so good that they are worth recording.

Haricot beans were prepared according to the directions given in an appendix to the article quoted above. They were first soaked in clean water for 24 hours and then placed in tin trays for 48 hours to germinate. Old ration biscuit tins, cut in half longitudinally and freely perforated with holes, were found serviceable for this purpose; they were easy to make, clean, and handle, and each half held 7 pounds of beans-a day's dose for 28 patients. Since germination takes about 48 hours at a temperature of $60^{\circ} \mathbf{F}$., it can easily be carried out in this country in May, when the mean temperature is $67^{\circ}$. The whole process is very simple, the only essentials being that the seeds must be kept moist, but not shut off from free circulation of air. After germination ten minutes boiling was ample to fit the beans for eating.

In addition to general use for many patients, two wards, each containing 27 beds, were specially devoted to the purpose of comparing the therapentic values of these germinated beans and fresh lemon juice. Scurvy cases were admitted to these two wards alternately without selection. In one ward each patient was given $4 \mathrm{oz}$. of fresh lemon juice daily, the juice being expressed in the ward, sweetened slightly, and given as a measured dose by the sister. In the other ward each patient received a portion

1 Harriette Chick and $\mathbf{E}$. Margaret Hune: The Distribution Among Foodstuffs (especially those Suitable for the Rationing of Armies) of the Substances Required for the Prevention of $(a)$ Beri-bert, and
Scurvy, Journal of the R.A.M.C., xxix., No.2, August, 1917, p. 121. of germinated beans which had weighed $4 \mathrm{oz}$. in the dry state, half being taken at dinner and half at tea. In respect of other forms of treatment, such as tonics and local treatment to the mouth, no difference was made between the two wards.

A certain amount of prejudice against the beans had to be contended with. Though perfectly good to eat, it cannot be said that they always looked appetising, and some with a dark husk had a disagreeable sour taste. These disadvantages might have been masked by mixing the beans in a general stew, but it was thought better to serve them apart in order to ensure some accuracy of dosage and that the cooking should be limited to the shortest possible time. Apparently, however, the greatest difficulty was based on the fact that these beans are regarded as pig food by some Serbs, and this necessitated frequent explanation of their functions through an interpreter.

Since the cases were mild and presented but slight changes, it was not easy to make comparisons. In no case did fresh scorbutic signs appear after treatment was started, and in many local lesions were limited to the gums and the hair follicles. The degree of general cachexia present was not a safe criterion of the severity of the disease, because in many instances it was partly due to chronic malaria. Hair follicle changes are not a good guide to progress, since they always take many weeks to return to normal, however quickly the active tendency may be abolished. Alteration in the condition of the gums seemed to be the best index, although allowance had to be made for the presence of dental caries and previous pyorrhoea alveolaris.

In the special wards 30 patients were treated throughout with lemon juice, and 27 with beans. Contrasting them as regards severity of disease at the commencement of treatment, those treated with beans were, on the whole, slightly worse. The difference would be too small to mention, save that it justifies the definite statement that the bean cases were certainly as severe as the lemon cases. Comparing the results of treatment, there is a small but definite difference in favour of those treated with beans, 70.4 per cent. being cured within four weeks, as against 53.4 per cent. of those treated with lemon juice. These figures favour the bean cases unduly, the real difference being better expressed by the time taken for the gums to return to normal, which was $3 \cdot 1$ weeks for bean cases and 3.4 weeks for lemon cases.

In another series of 21 cases beans were not given until the patients had failed to make satisfactory progress after an average of four weeks' treatment in hospital by other means. These, although they had shown themselves rather refractory to ordinary treatment, all showed acceleration of progress when put on the beans, and in some the difference was very marked. For example :-

CASE 17.-Age 51. No previous scurvy. Patient had suffered from symptoms of scurvy, sore gums and pains in the legs, for three weeks before admission to hospital at $X-$ He was transferred to this hospital after 25 days $^{3}$ treatment at $X-$ On admission his gums still showed marked swelling and tendency to bleed, but there was no dental sepsis to delay healing. The hair follicles on the front of the legs and thighs showed a tew fresh petechial hæmorrhages. There were no big muscle or joint hæmorrhages. General anæmia was marked. After 26 days' further treatment with $4 \mathrm{oz}$. of lemon juice daily, local treatment to the gums by hydrogen peroxide and tincture of iodine, and administration of an iron and arsenic tonic, so little improvement was seen that the treatment was changed by the simple substitution of the lemon juice by $4 \mathrm{oz}$. of germinated beans. In five days definite improvement was apparent, in 13 days the gums were noted as practically normal and in 20 days as quite normal.

These clinical results, then, confirm the experimental results of Dr. Chick and Miss Hume, and permit the definite conclusion that dry beans develop, upon germination, an amount of antiscorbutic vitamine at least equal to, if not greater than, that contained in fresh lemon juice.

II.-Deductions from Consideration of the Rations upon whioh our Patients became Scorbutic.

(a) Meat.-Of 132 cases of scurvy whose previous diet was investigated last year all had received a ration of frozen fresh meat practically every day; and of 175 investigated this year very few had received it less than three times a week. Fresh raw meat is known to contain a small amount of antiscorbutic vitamine. To what extent freezing and sabsequent cooking are respectively responsible for the destruction of this vitamine remains uncertain, but it is obvious that between them they render meat practically useless as 
an antiscorbutic. In the case of tinned meat the vitamine seems to be completely destroyed by the temperature needed in the process of tinning, so that for practical purposes the meat-supply of troops in the field must be regarded as totally devoid of antiscorbutic properties.

(b) Lime juice. - In the past lime juice had a well-deserved reputation as an antiscorbutic. The vast majority of the patients admitted to this hospital had never received a single dose. Three, however, were exceptions, having developed scurvy after taking a small quantity every day for a month. These become significant in conjunction with the fact that Dr. Chick and Miss Hume found by experiment that modern preserved lime juice has but feeble antiscorbutic power, and suggest that it would be unwise to place too much reliance upon modern supplies for prophylaxis. Probably, as suggested by Dr. Chick and Miss Hume, the lime vitamines are destroyed by modern methods of manufacture. 2

(c) Fresh fruit.-According to their own statements, not one of the patients seen this year or last year had received any fresh fruit previous to admission to hospital. Oranges and lemons become available in the early spring, but even when a sufficient quantity can be obtained they are difficult to store and transport, owing to their bulk and perishable nature. This difficulty seems to have prevented them from reaching the troops at the front last year, and would operate in the same way in future. Further, these fruits cannot be obtained in sufficient quantity in the early months of the winter, the time when they are most needed to combat the early stages of vitamine deficiency.

(d) Vegetables. - In the last two winters the vitamines received by scurvy patients before admission to hospital had been limited to those contained in potatoes and onions, with the addition, late in the season, of spinach. The potatoes, when issued, were always greatly diluted with rice, so that the amount received by each man was very small. This year out of 175 patients 101 stated that their weekly allowance, of vegetables had been one, or at most two, issues of potatoes with rice, and one issue of onions. Most of these were admitted early in the season. Fifty-eight men, most of whom were admitted rather later, had fared better, receiving potatoes with rice twice a week, onions once or twice a week, and spinach once or twice a week. This should be a fairly generous supply of vitamine, and is unlikely to be exceeded next winter, but the fact remains that these men became scorbutic.

Sixteen patients were of special interest, because their diet for a month before admission should have contained sufficient vitamine not merely to prevent scurvy but actually to cure it. Eleven of these had received "plenty" of onions daily, most of them having also had potatoes with rice twice a week and spinach twice a week. 'Two, in addition to the above, had also received a small dose of lime juice every day, and the remaining three had received spinach every day. Now, onions, potatoes, and presumably spinach are very rich in antiscorbutic vitamine in the raw state. Granted that these men may have reached a serious stage of vitamine deficiency before their diet became so generous, the fact that they did develop scurvy on the above diets is difficult to explain except on the assumption that nearly all the antiscorbutic vitamine of the vegetables must have been destroyed in the process of cooking. This point is referred to later.

\section{III.-Conclusions Regarding Preventive Measures for the} Coming Winter.

(a) Preventive measures should be commenoed not later than the end of November and should be continued through the whole winter. - It is essential to remember that the occurrence of the first case of scurvy in an army does not mark the beginning of vitamine deiciency. There is a prescorbutic stage, comparable to the incubation period of infective disease, during which, although the troops may appear to be in excellent health, they are in reality far from physically fit. In the case of troops rationed as the Serbian front line regiments were during the last two winters the duration of this stage probably varies between two and four months. Apart from the possible occurrence of clinical scurvy later on, so long as an army is in this prescorbutic stage of vitamine deficiency it is in danger of breaking down from various causes, such as extra physical stress, exposure to severe weather, or the presence of epidemic infections. In other words, an army deficient in vitamine is an army of deficient vitality, although until recognisable scurvy actually breaks out there is nothing to demonstrate the fact and serve as a warning.

Daring the last two spring seasons scurvy was sufficiently prevalent amongst Serbian troops to show that the Serbian
Army, as a whole, was suffering from this vitamine deficiency to a serious extent. Clinical scurvy appeared in November, and continued until May. Vitamine deficiency must have commenced in November and continued until May, so that in any army placed under similar conditions in the future preventive measures should begin not later than the end of November, and be continued throughout the winter.

(b) The destruction of antiscorbutic vitamine which takes place in oouking must be avoided as far as possible. - The exact mechanism of this destruction is not known, but it is generally allowed that vegetables lose antiscorbutic power when cooked, and some of our patients mentioned above afford clinical proof of the fact. Simple heat and altered chemical reaction are both under suspicion as the destructive agents. Dr. Chick and Miss Hume quote an experiment which shows that cabbage leaves lose half their antiscorbutic power when boiled for half an hour, but more experimental data dealing with this point are needed.

Recently Harden and Zilva ${ }^{3}$ have shown that the antiscorbutic principle of orange juice is rapidly and permanently destroyed when the juice is made $N / 20$, or $N / 50$, alkaline with caustic soda, and they suggest that any cooking entailing alkalinity will injure the antiscorbutic potency of the substance cooked. Army cooking of vegetables does not entail alkalinity. Some salt is always added to the water in which vegetables are boiled, and this may be either " issue" salt or salt in which bacon has been packed. In distilled water both of these give a solution which is neutral to litmus and is certainly not alkaline to phenolphthalein. A raw potato is acid to litmus and it remains acid when fully cooked. The water in which potatoes have been cooked remains neutral. Onions are acid when raw, and not only remain acid when fully cooked, but impart a definitely acid reaction to the water in which they have been boiled. The same is true of germinated beans. These also not only remain acid when cooked, but impart some acidity to the water in which they have been boiled. In consequence, the question of alkalinity produced by cooking does not exist as far as Army methods are concerned, and in the present state of our knowledge it will be safe to regard heat as the destructive agent and to reduce the heating of all vegetables to the absolute minimum required to make them digestible.

The reduction of raw potatoes to the condition of a digestible cream would be too difficult to carry out on a large scale without the provision of some special apparatus of the type of a "Hercules press"; but small quantities of onion and spinach would be sufficiently digestible if chopped or minced into fine particles. If thoroughly mixed with a stew at the completion of cooking these vegetables should be well taken in the raw state, and would add very greatly to the antiscorbutic value of the diet.

(c) The addition of some fresh vitamine-containing substance being needed germinated pulses, as suggested by Dr. Chiok and Miss Hume, would provide the easiest and cheapest method of effecting this addition.-As shown above, modern lime juice is not to be trusted as an antiscorbutic, and fresh fruit and vegetables (in the quantities available) have failed to prevent scurvy for two years in succession, but germinated haricot beans, even when fully cooked, contain at least as much vitamine as fresh raw lemon juice. Other pulses which might be germinated and would probably give as good a result are peas, beans of any variety, and unmilled lentils. It only remains to show that it would be practicable to provide these for troops in the field.

In this country germinated pulses would only be required during the winter, a season which has the disadvantage of necessitating the provision of some artificial heat to ensure germination. This disadvantage is counterbalanced by the fact that the movement of troops is lessened during the winter months.

The advantages of these dry seeds over all other forms of fruit and vegetables, both for storage and transport, are obvious. Since they double in weight and bulk and require to be kept moist when germinated, this process should be carried ont as near the site of consumption as possible. In stationary trench warfare it should not be necessary to attempt germination in the actual front line, because the supply of vitamine by this method is so generous that it would suffice for preventive purposes if given every other week, or every other fortnight, when the troops were in rest.

3 A. Harden and S. S. Zilva: A Note on the Susceptibility of the Antiscort 
Should, however, a battalion be compelled to stay in the front line for longer than a fortnight it would not be difficult to supply it with pulses already germinated, since at most two hundredweight $(100 \mathrm{~kg}$.) per day would be needed for a thousand men, and this weight represents so much food transported as well as so much vitamine.

In the case of a war of movement local conditions and temporary needs and opportunities would have to be considered as they occurred, again always keeping in mind the fact that the supply need not be continuous for preventive purposes, and that these pulses provide their full value of food as well as their supply of prophylactic vitamine.

As regards germination, the preliminary soaking for 24 hours can be done anywhere. For germination itself the essentials are moisture and protection against cold, but without the exclusion of air. The rate of germination varies with the temperature and the type of pulse. Seeds were not obtained here until too late to test them in cold weather, but, judging by the season at which peas and beans are sown in Fngland, no cold short of definite freezing would arrest the process completely, though it would, of course, lengthen the time required for growth to take place. Hence, if facilities are lacking for keeping a supply in process of germination, the time taken must be shortened by the provision of artificial warmth.

The space required and needing to be kept warm is very small. Allowing $2 \mathrm{oz}$. per man per day, a dose which should be ample for prophylaxis, a day's supply for 1000 men could easily be accommodated in a space of 30 cubic feet. On an average of three Gays for soaking and germination this means that a space of 100 cubic feet would suffice to provide a continuous supply for 1000 men.

In Salonika during the three cold months, December (mean temperature $46^{\circ} \mathrm{F}$ ), January (mean temperature $42^{\circ}$ F.), and February (mean temperature $45^{\circ}$ F.), artificial warmth would .be essential. For this a building or tent would be a great advantage, but failing these the necessary warmth might still be obtained by means of a hotbed any where within reach of fresh horse or mule manure. During November (mean temperature $52^{\circ} \mathrm{F}$.) and March (mean temperature $50^{\circ} \mathrm{F}$.) germination could be carried out in the open without artificial warmth, provided that some protection were given at night and during spells of bad weather. $A$ few boxes and some old sacking would provide all the protection needed.

The beans soften so much in the process of germination that ten minutes' boiling is ample to cook them fully. If crushed or pounded they can be eaten raw, but this should rarely be necessary unless the supply ran short.

Allowing for the fact that beans are food and lemons are not, the vitamines supplied by the former are really obtained almost free of cost. Even if no allowance is made for the food value of the beans, the cost of the vitamines supplied by them would still be only 60 per cent. of the cost when supplied by lemons.

\section{General Conolusion.}

The statement of Dr. Chick and Miss Hume that germinated pulses are richly endowed with antiscorbutic vitamines is amply confirmed by the fact that germinated beans were found quite as potent as raw lemon juice in the treatment of scurvy. Their suggestion that germinated pulses should be used for the prevention of scurvy is capable of practical application, and would be the easiest and cheapest method by which to prevent the occurrence of scurvy in an army in the field.

In the case of vegetables cooked in the Army manner the destruction of vitamine which takes place cannot be ascribed to the production of alkalinity.

In conclusion, my thanks are due to Lieutenant-Colone A. R. Greenwood, R.A.M.C., for permission to publish these cases; to Miss M. J. Ahern for careful clinical notes; and also to Quartermaster-Sergeant Andrews, R.A.M. C., for constant supervision of the germination and cooking of the beans.

Death of Henry albert Pattinson, M.R.C.S. Eng., L.R.C.P. Irel.-Mr. H. A. Pattinson died recently at Seafield House, Seaton, Devon, in his 79th year. He had practised in Seaton for more than 50 years, and had been medical officer of health for the town since the formation of the Seaton Urban Council in 1892. Fxpert at all games, he was prominent in founding the Seaton Cricket and Lawn Tennis Clpbs and the Axe Cliff Golf Club, of which he was honorary secretary for many years.

\section{BEER AND SCURVY.}

\author{
SOME NOTES FROM HISTORY.
}

$$
\begin{gathered}
\text { Br A L I CE H E D D RSON SM I TH. } \\
\text { (From the Lister Institute of Prerentine Medioine.) }
\end{gathered}
$$

Captain Hamilton Dyke's account in ThE LANCET of Oct. 19th of an outbreak of scurvy in the South African Native Labour Corps, and his demonstration of the useful place taken by kaffir beer in the diet of these natives in their homes, are very interesting in view of the use of small beer of various kinds in the Navy and other ships, and the belief that long obtained in its antiscorbutic power. During a search in the Admiralty records for information on another subject some points have come up in this connexion that it may be worth while to record briefly.

Long History of Use of Spruoe-beer against Sourvy.

Beer was held for generations to have considerable value as an antiscorbutic, and was long used as such on seavoyages. The virtue of it was not attributed solely to the various ingredients from which it was brewed but largely to the fermentation itself, and beers were made of different materials and in different ways. The early spruce-beer, which was indebted for its potency, at least in some methods of preparing it, to the fresh leaves from which it was named, has a long history. It was used by explorers at least from the time of Willem Barentz ${ }^{1}$ and probably before that. Barentz carried on his voyages in 1594-97 casks of the "jopen-bier" or "sprossen-bier" that was then made round the Baltic with the green leaf buds or sprossen of the fir-tree in it, the original spruce-beer. The sprossen used were generally those of the spruce (Pruoe or Prussian) fir (Abies excelsa). In this beer the green buds seem sometimes to have been added to the fermented malt, as hops are added now. Alternatively the fir was boiled in water and the infusion fermented, and since a mere infusion of sprucetips or the fresh spruce-tips eaten as a salad have proved useful, it is probable that the original spruce-beer was of some value. Dr. Lind says ${ }^{2}$ (in 1757) :-

"A simple decoction of the tops, cones, or even bark and wood of these trees is antiscorbutic, but it becomes much more so when fermented, as in making spruce-beer. Spruce should be carried to sea; if not, the common fir-tops used for fuel should be first boiled in water and the decoction afterwards fermented with mollasses, in the common method of making spruce-beer."

He himself prescribed at Haslar, with beneficial results, a daily pint of "strong beer medicated with the most powerful antiscorbutic herbs." It was long the custom on distant voyages al ways to make spruce-beer on touching land, if it were possible.

But the name spruce-beer came to be applied often to beers that were entirely innocent of the fresh sprossen, as in the modern Dantzic spruce, whether or not the spruce flavour was introduced. The essential element, of course, from the point of view of scurvy, was the freshness of the vegetable ingredient, and, as has happened in the history of other antiscorbutics, the belief in the value of the drink persisted after the elimination of the element on which that value depended. We find later an Arctic officer stating that spruce-beer was brewed on board his ship when she was in the ice several degrees of latitude beyond the highest at which the fir grows. This beer was sugar or malt beer, flavoured with " essence of spruce."

Value of Sweetrort.

The value of fresh germinated barley has been shown anew recently by Fürst, ${ }^{3}$ and the actual experience of its use seems to suggest that malt which is not "highly dried," as in the modern manner, probably retains much of its potency. Even in a simple brewing process the beer may

Companion papers entitled (1) The Relative Content of Antiscorbutic Principle in Limes and Lemons together with Some New Facts and Some Old Observations Concerning the Value of "Lime Juice" in the Prevention of Scurvy, (A) Experimental Inquiry, by Harriette Chick, E. Margaret Hume, and Rutb F. Skelton, (B) Historica

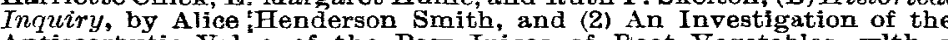
Antiscorbutic Value of the Raw Juices of Root Vegetables. wlth a View to their Adoption as an Adjunct to the Dietary of Infants, by Harriette Chick and Mabel Rhodes, appeared in THE LANCET of Nov. 30th, 1918 (p. 735), and Dec. 7th, 1918 (p. 774), respectively. 1 " Journal of the Three Voyages of Willem Barentz," Gerrit de Veer, published by the Hakluyt Society, 1876.

2 A Treatise on the Scurcy, Lind, 2nd edit., 1757.
3 Furst : Zeitschrift f. Hygiene, 1912, vol. Ixxii. 